\title{
Delivery of Learning Modules through the Telegram Social Media Application: Views of Post Graduate Diploma in Education Distance Students of University of Education, Winneba
}

\author{
Francis Owusu-Mensah ${ }^{1}$, Humphrey Augustine Kpengnibe Pufaa ${ }^{2}$ and David Kofi Sakyi ${ }^{3}$ \\ 1,2,3 University of Education, Winneba \\ Institute for Distance \& eLearning \\ Post Office Box 25 \\ Winneba, Ghana
}

\begin{abstract}
The study investigated the views of Post Graduate Diploma in Education (PGDE) Distance Students (2017/2018 Year Group of UEW, Winneba) Winneba Study Centre on the delivery of learning modules and leaning convenience in the use of the telegram application (app). The study adopted the sequential explanatory mixed methods design, characterized by the collection and analysis of quantitative data followed by collection and analysis of qualitative data. Questionnaire and interviews were instruments used to collect data for the study. The population for the study was all hundred (100) Post Graduate Diploma in Education (PGDE) Distance Students of the Winneba Study Centre. Simple random sampling technique was used to select two-thirds (75 students) of the population. Sixty (60) of the respondents successfully completed the online questionnaire. Ten (10) of the participants were traced to respond to the qualitative questions for the study. Data obtained from the online questionnaire were analyzed and presented in tables and charts. Data from the individual interviews were analyzed thematically. A major finding was, the telegram app facilitated the timely delivery of learning modules. The study concluded that, the telegram app proved to be efficient in not only the delivery of learning modules for the students but also very convenient an app for distance learning. The study recommends the adoption and integration of telegram app in the distance education programme in an attempt to resolve the late delivery of learning modules as well as learning convenience for the students.
\end{abstract}

Keywords - distance learning; learning convenience; education; technology; internet.

\section{Introduction}

Tertiary institutions in Ghana have started to use Internet and World Wide Wed (WWW) to support teaching and learning with the understanding that technology can be a better vehicle to support the education of the new era because internet education enable dissemination of 
teaching materials easily in most cases and the irony of this is that, some tertiary institutions in Ghana are still lacking in this technology for teaching context; hardly can their education rationales be seen of the construct which are consistent with the aforementioned paradigm shift in most of their educational processes. Potentials of the Internet and WWW have still not been maximized to the fullest in the tertiary educational sector in Ghana and makes learning uninteresting by skewing it away from the technological demands for educating contemporary technology thirsty students.

The tremendous technological developments in internet technology have brought an unprecedented excitement and opportunity in education and supports the fact that technology, for that matter social media has and continues to be a magnetizing platform for 21 st Century lecturers and students for interaction as well as facilitate teaching and learning. It is therefore imperative for higher institutions of learning like UEW with special reference to the Institute for Distance and eLearning to adopt a social media platform to support its teaching and learning programmes.

Generally, the use of telegram social media platform is to prove that the effective integration of virtual learning at the Institute for Distance and eLearning has a great potential resting in the telegram app. This study is meant to project the perceptions of the distance education students about the role of the telegram social media platform in enhancing their learning.

\section{Statement of the Problem}

In our effort to keep pace with the $21^{\text {st }}$ Century teaching and learning, the University of Education (UEW) has started a vigorous integration of ICT in its teaching and learning process. More especially the distance education programme of the university has witnessed a rapid paradigm shift from our reliance on the print mode to the hybrid mode where e-learning is being part of its delivery.

A number of factors play key roles in the academic achievements of higher institutions of learning. Whereas some of the factors are institutional, others can be attributed to the students. In the case of higher institutions of learning, delays in the dispatch and receipt of learning modules at the various study centres and rescheduling of tutorials go a long way to impede the pace of teaching and learning [45]. Poor health, loaded work schedules and other social commitments on the part of the distance education students also impede the pace of teaching and learning and go a long way to explain some of the reasons why a number of distance students absent themselves from tutorials through-out the semester and only resurface for quizzes and end of semester examinations [12]. Heavily scheduled working students such as bankers, business professionals, force and health workers; are the worst victims of these challenges [40] Inadequate time for studies to enable them to catch up with colleagues was their main challenge. Another challenge that they face in their distance learning is the inconvenience of having to carry their heavy learning modules with them to work among others. Before the introduction of the telegram app, distance students who participated in the study had to wait till almost the end of the semester to take delivery of hard copy of learning modules.

There was the need for the Institute to research into alternative ways of addressing student challenges regarding the delivery of learning modules and its convenience. The telegram app 
was resorted to in 2017 as an intervention. After two years of its introduction, the Institute decided to seek the views of beneficiaries of the intervention to ascertain the effectiveness of the Telegram App in delivery learning modules and how convenient the app was in addressing the challenges of busy scheduled students of distance education in PGDE at the Winneba Study Centre of the University of Education, Winneba.

\section{Research Objectives}

The research was guided by the following research objectives:

1. To investigate into the views of heavily scheduled professional Post Graduate Diploma in Education Students on the delivery of learning modules with respect to the use of the telegram social media app.

2. To investigate into the convenience of the telegram social media app for Distance Learning with emphasis on the views of heavily scheduled professional Post Graduate Diploma in Education (PGDE) Students of the University of Education, Winneba.

\section{Research Questions}

The following research questions were formulated by the researchers for the study:

1. What are the experiences of PGDE students in the use of Telegram Social Media App for delivery of learning modules?

2. How convenient is the Telegram Social Media App to PGDE students of UEW?

\section{Literature Review}

\section{Distance Education}

Distance education is the kind of education in which students may not always be physically present at a school. In other words, you learn, study, and qualify in your chosen subject online without having to attend an exam center, a college building, or university campus. According to [41], the majority of distance education today takes place using the Internet, now readily accessible for the vast majority of students whether in their own homes or at facilities such as local libraries.

According to [32], distance learning or distance education, is not a future possibility for which higher education must prepare, it is a current reality creating opportunities and challenges for educational institutions; a reality offering students expanded choices in where, when, how, and from whom they learn; a reality making education accessible to ever larger numbers of persons. The facts that the number of universities offering distance education programs have increased, that the courses have become more varied and that the number of students applying these programs is rising, raise the question of whether the given education is as efficient as it could be. That is why researchers are continuing to develop and improve online activities [25]. 
In addition, individuals who were unable to continue their undergraduate, graduate, or postgraduate education, for whatever reason, may now do so through distance learning. Therefore, distance learning offers equality of opportunity to individuals [24].

\section{Evolution of Distance Learning}

Distance education, in some form, has been around for decades. Before 1900, the communication system of the Roman Empire set the stage for distance learning, long before the idea of such a phenomenon was conceived. Inventions during this time of the printing press and the postal service made possible the printing of many copies of learning materials to be distributed to many individuals. Correspondence education began toward the end of the 19th century, and in the 20th century, radio, telephone, cinema, television, programmed learning, computers, and the Internet all became tools of the new method of distributing education [10].

Taylor [43] identified five main generational stages when it comes to the evolution of distance learning, namely the $1^{\text {st }}$ Generation, $2^{\text {nd }}$ generation, $3^{\text {rd }}$ generation, $4^{\text {th }}$ generation and the $5^{\text {th }}$ generation. $1^{\text {st }}$ generation is characterized by the correspondence model where the mode of teaching and learning is via print. With the $2^{\text {nd }}$ generation stage, institutions of learning adopt the multimedia model which is characterized using print, audio tapes, video tapes, computerbased learning and interactive video. The $3^{\text {rd }}$ Generation which is a buildup on the $2^{\text {nd }}$ generation stage is known as the tele learning model which is characterized using audio teleconferencing, video conferencing, audio graphic communication, broadcast tv/radio and audio tele conferencing. Fourth generation stage is characterized by the flexible learning model which has features including interactive multimedia online, internet - based access to www resources and computer-mediated communication. The last of stages when it comes to distance education evolution is the $5^{\text {th }}$ generation which is characterized by the intelligent flexible learning model which has interactive multimedia online, internet-based access to www resources, computermediated communication using automated response systems and campus portal access to instructional processes and resources features.

The University of Education Winneba and for that matter the Institute for Distance and eLearning associates itself with the $4^{\text {th }}$ generational stage of distance education.

\section{Challenges of Distance Learning}

Despite the expanding growth of Open and Distance Learning (ODL) and its benefits, students who enroll with ODL have been shown to face many challenges related to individual, institutional and instructional [3], [4], [7], [29], [30]. In his works, [8] identified three distinct categories of challenges facing ODL students: situational, institutional and dispositional. According to Cross, situational challenges include job and home responsibilities that reduce time for study. Institutional related challenges include poor logistics system or a lack of appropriate advising [27]. Dispositional challenges are related to learners' own attitudes and feelings.

Berge et al [1] classified challenges of distance learners as situational, epistemological, philosophical, psychological, pedagogical, technical, social, and/or cultural related challenges. 
Zirnkle [46] identified specific challenges facing distance learners as programme costs, lack of equipment and infrastructure, instructional concerns and poor technical assistance. Other challenges documented by Zirnkle are inadequate feedback and poor teacher contact, alienation and isolation, and poor student support services. Garland [14] identified some situational challenges for students to be persistence in distance learning. These include poor learning environment and lack of time. For example, students felt that the course took more time than anticipated because they failed to judge the demands of work, home and school. Kember [21] argued that poor time management leads to challenges such as learners' inability to integrate the demands of off campus study with family, work and social commitments.

Kamau [20] found that, without an effective learners' support services system that provides onsite face to face, timely feedback on student performance and access to library services, student achievement will be undermined and dropout rates and procrastination will increase.

ODL also presents new challenges in information dissemination, especially in developing countries.

Mossberger et al [34] observes that technical competence needed in order to have effective access to contemporary ICT is a challenge to distance learners.

According to Carr [6], in the US drop-out rates of students from ODL programmes range from $20 \%$ to $50 \%$. The OECD (2000) reported that drop-out rates range from $20 \%$ in the United Kingdom to $45 \%$ or more in Austria, France, and Portugal. In Australia, drop-out rates range from $35 \%$ to over 55\% (Fozdar et al., 2006). In African countries the drop-out rate is estimated to be over $50 \%$ [11].

\section{Social Media in a Virtual Environment}

Several definitions gave been given by different authorities about the definition of social media. According to Ololube [36], Social media is the collective of online communications channels dedicated to community-based input, interaction, content-sharing and collaboration. Facebook, twitter, instagram, telegram, Wikipedia etc... are popular free social networking website that allows registered users to create profiles, upload photos and video, send messages and keep in touch with friends, family and colleagues.

Powell, et al [38] also argued that Social media are computer-mediated technologies that allow the creating and sharing of information, ideas, career interests and other forms of expression through virtual communities and networks. Powell et al [38] further explained that social media use web-based technologies, desktop computers and mobile technologies (e.g., smartphones and tablet computers) to create highly interactive platforms through which individuals, communities and organizations can share, co-create, discuss, and modify user-generated content or pre-made content posted online.

Kidwell et al [22] also opined that social media is a type of online media that expedites conversation as opposed to traditional media, which delivers content but doesn't allow readers/viewers/listeners to participate in the creation or development of the content. 
Internet-based software and interfaces that allow individuals to interact with one another, exchanging details about their lives such as biographical data, professional information, personal photos and up-to-the-minute thoughts. Social media originated as strictly a personal tool that people used to interact with friends and family but were later adopted by businesses that wanted to take advantage of a popular new communication method to reach out to customers, for example, by informing them of sales and offering them special coupons. Through social media, anyone with internet access can interact with millions of people online. It is not necessary to be a journalist, a politician, a CEO or to hold any other position that was traditionally necessary to be able to disseminate one's thoughts or ideas to a wide audience [33].

According to Cubukcuo lu [9] Social networks could be one of the solutions to utilize virtual learning environments anytime, anywhere, and at any pace.

Heibert and Harper [16] emphasize students' increased involvement in communication where social networks are a vehicle for this purpose. Junco and Cole-Avent [18] mention social networks as one of most engaging technologies that students use. Social networks create such a degree involvement that students make comments, contribute to discussions, and share experiences.

Open-source web-based tools are used for building an "online learning community". Blogs, wikis, social bookmarking, feeds, internet telephones, podcasts, and photo, link, and videosharing sites are used to interact with members in the community [15], [42]. It should be noted that the effective use of these tools in virtual environments also helps to improve student engagement. Here, students can play various active roles as a learner and teacher, and peer tutors [2] through any type of learning resource or events that help learners to acquire competences.

Oradini and Saunders [37] consider social network usage as a practical and more interactive alternative to the involvement of students within large physical classrooms. They add that, in addition to academic development, social networks help diverse groups of students to settle and integrate. The use of interactive technologies can increase student engagement as they collaborate with both their peers and instructors [5].

Cubukcuo lu [9] also argued that, there are many examples of social network usage in higher education around the world and Oradini and Saunders [37] implemented the "Connect" system, and discovered that only certain students were using this social network for communicating with peers with similar interests. Some of the students believed that it is unnecessary to have another social network such as Connect, because they did not have enough time or were already enrolled in many networks including Facebook. Another finding related to the reason for not using networks frequently for academic purposes was that students wanted to see their tutors also participating in the system. The more faculty members are encouraged and work with students in the online environment for educational purposes, the more contributions are made by students.

Juang [19] developed a WIRE instructional model on Facebook and conducted a quasiexperimental research by applying this model. Many of the respondents claimed that using 
Facebook developed their sense of achievement and understanding of the lessons. On the other hand, much is important to be able to adapt the use of these technologies to the teaching and learning environments in higher education. This usage may promote students' active and effective learning by engaging them both in classroom and online. Grodecka et al [15] comment that new technologies support, even facilitate, constructivist learning where students gain knowledge and build their skills through activities and experiences with other learners. They add that learners develop many important skills such as collaboration, negotiation, reflection, constructive criticism, selection, and information analysis. The learning theories that form the basis of technology use in education are connectivism which is one of the recently emerging learning theories of the digital age [23]. Online learning communities will also form communities of practice in a time frame [42]

\section{Convenience of Social Media to Users}

According to Madge et al [28] (2009), it is definitely not an exaggeration to say that social media websites are evolving to be (or are already) integration into our lives. Especially for the younger generation, they are growing up in a world that seems smaller because communication has become much easier as compared to their grandfathers' time. Interaction with a complete stranger from another side of the world doesn't seem that strange after all. The key is to remain competitive and to bring the resources to your advantage. Identify your needs to attain effective communication and then choose the right channels to broadcast your message.

Tedd [44] opined that with "virtual learning, students can study at a time and location that suits them and can quickly locate misplaced notes". Madge et al [28] further argued that with more advanced technology, better accessibility and better user experience are made possible. We can definitely expect a proliferation of social media websites and applications. People are interdependent and vital networking with others is definitely an asset.

Juang [19] is also of the view that this dependence on social media is a phenomenon that has grown exponentially over time. While the need for communication has not changed greatly, the reliance on social media has; this transition in society is one that users should be cognizant of Social media's convenience has led to society growing far too dependent on its networking resources and its power to disseminate messages.

Juang [19] argued further that, as the history of communications reveals, the idea of sharing your personal experiences with others and feeling connected to the larger world is not new: what is new is efficiency. Due to the access of computers, tablets, and phones, people are posting more and more to social media. The technological changes in social media have continued to advance rapidly, transforming older technologies to make them simpler and more effective.

It is important to grasp that although we have the same goals as past generations, we communicate today through more efficient means. We now find ourselves at a juncture in communications, as social media is taking over and drawing our attention unlike ever before. Without a doubt, social media has altered the way people communicate in their day-to-day lives. It is common to see groups of people routinely walking to a destination with their heads buried in their phones, distancing themselves from authentic social interaction. Some feel an 
obligation to social media and daily communication, struggling to go long periods without it: if they are not online, they risk being left out of some social event, a phenomenon known as FOMO, or Fear of Missing Out. In reality, they are probably just missing a few photos posted by friends recalling the previous night or a text from a friend about missing a television show [17].

\section{Telegram Messaging App and Convenience for Distance Learning}

Telegram is a messaging app with a focus on speed and security. It is super-fast, simple and free. The desktop version was first lunched in the year 2013. Telegram can be used on all devices at the same time, with messages sync seamlessly across any number of phones, tablets or computers and connects from most remote locations. In most cases, typing texts on cellphones can be cumbersome for some users due to the minute nature of their keyboard and visual challenges, leading to multiple typographical errors which are capable of misleading students in certain educational concepts during virtual lessons. As such, Telegram Desktop App becomes a substitute. Telegram Desktop facilitates easy usage of computer keyboard and easy correction of typographical errors and automatically syncs messages from your phone with your computer using Telegram's encrypted cloud. All it takes is to install it and log in to your account and all messages, documents, photos and videos will be synced for you from the secure cloud. Thanks to Cloud Drafts, a user can even start typing on his/her phone, and then continue on the desktop when one reaches home or work. With the telegram app, there is no need for emails. Telegram desktop is many times faster and handles attachments like a pro. One has to simply share his/her t.me/username with those who want to reach you. Simply opt for Gmail bot (https://t.me/gmail) if you are interested in looking for an easy way to get your emails right in Telegram. This helps one to stay in touch with those who insist on using antique methods of communication.

Telegram has embedded in it a number of features that makes it a very convenient social media app for distance learning. Such features include secret chat, huge file sharing sizes, super groups and public channels, security among others.

Telegram's "secret chat" feature allows a user to have a conversation with end-to-end encryption among other security options. There are notifications for screenshots taken and you can't forward a message from a secret chat. You can also set a self-destruct timer, which will destruct your messages after a specified time. If you are looking for a secure messaging experience, Secret chat has got you covered. This supports individual counseling of learners concerning their academic work and private challenges which might impede their learning pace. Such private matters may relate to marital challenges, health related issues and other personal issues of learners which should not leaked into the public domain. Learners being aware of this security features of telegram will be able to open up and discuss freely their challenges with their counselors through the Secret chat section. This also paves the way for shy students who have personal challenges to discuss their problems with their counselors for the first time, without seeing each other face to face. Tutors can also handle disciplinary issues using the secret chat section privately instead of reprimanding students publicly when they misbehave. It is important to note that mature students are being tutored not children. Therefore disciplinary issues should be handled in privacy. 
Telegram, is based on MTProto Mobile protocol and brings end-to-end encryption with "Secret chats". It also has the cool self-destruct feature and notifications to users when a screenshot is taken by the recipient.

Telegram is quicker in sending messages due to its cloud sync feature. When it comes to usage, both WhatsApp and Telegram are very easy to use, with similar working apps. However, Telegram's gesture based UI makes things quicker and fun. Soft copies of learning materials are likely to reach learners quicker than the printed modules. Telegram supports stickers. The app lets you create your very own stickers through the @Stickers bot. You can preview and choose from different stickers available through third party websites, Reddit threads or even a third-party app.

In virtual classroom, these stickers are needed for motivating, rating and easing tension of students during the teaching and learning process for example, a sticker with a thumb up indicates good work, keep it up etc. whiles a clapping sticker indicates excellent work, bravo etc.... Distance education students with heavy professional schedules need such encouragement when it comes to learning.

\section{Methods}

The study adopted the sequential explanatory mixed method design strategy of the mixed method, which is characterized by the collection and analysis of quantitative data followed by collection and analysis of qualitative data. To obtain the necessary information concerning integrating social media (Telegram App) into Distance Learning at the Institute for Distance and eLearning of the University of Education Winneba, a descriptive survey was adopted for the study. The population for the study was all hundred (100) PGDE Distance Students of the Winneba Study Centre. Simple random sampling technique was used to select 80 students of the population. The sample size conforms with the sample size formula for finite population postulated by Krejcie and Morgan [26]. The selected sampled were required to fill an online instrument for the purpose of the study. Sixty (60) of the respondents successfully completed the online questionnaire. Twenty (20) out of the eighty sampled respondents could not however respond to the online questionnaire, irrespective that, the response rate was $80 \%$. Out of the sixty (60) respondents, ten (10) were traced to respond to the qualitative questions for the study. Online questionnaire was used as the main instrument for data collection from the respondents. The questionnaire was uploaded into an online data collection platform (Survey monkey) for easy access by the students. The link to the online instrument was uploaded to respondents via the telegram app. Data obtained from the online questionnaire were analyzed and presented in tables and charts.

\section{Results and Discussion}

This section presents the analysis of the responses in relation to the research question. The section is divided into two sub-sections; the socio demographic characteristics of respondents and discussion in line with research question. 


\section{2nd International Conference on \\ New Trends in Teaching and Education}

29-31 October, 2020

London, United Kingdom

occupation were the main characteristics of concern to the researchers. The respondents were not less than 15 years but more than 45 years in age.

Figure 1 displays the age distribution of the respondents.

Figure 1: Age distribution of Respondents.

\section{Pie Chart Showing Age Distribution of Respondents}

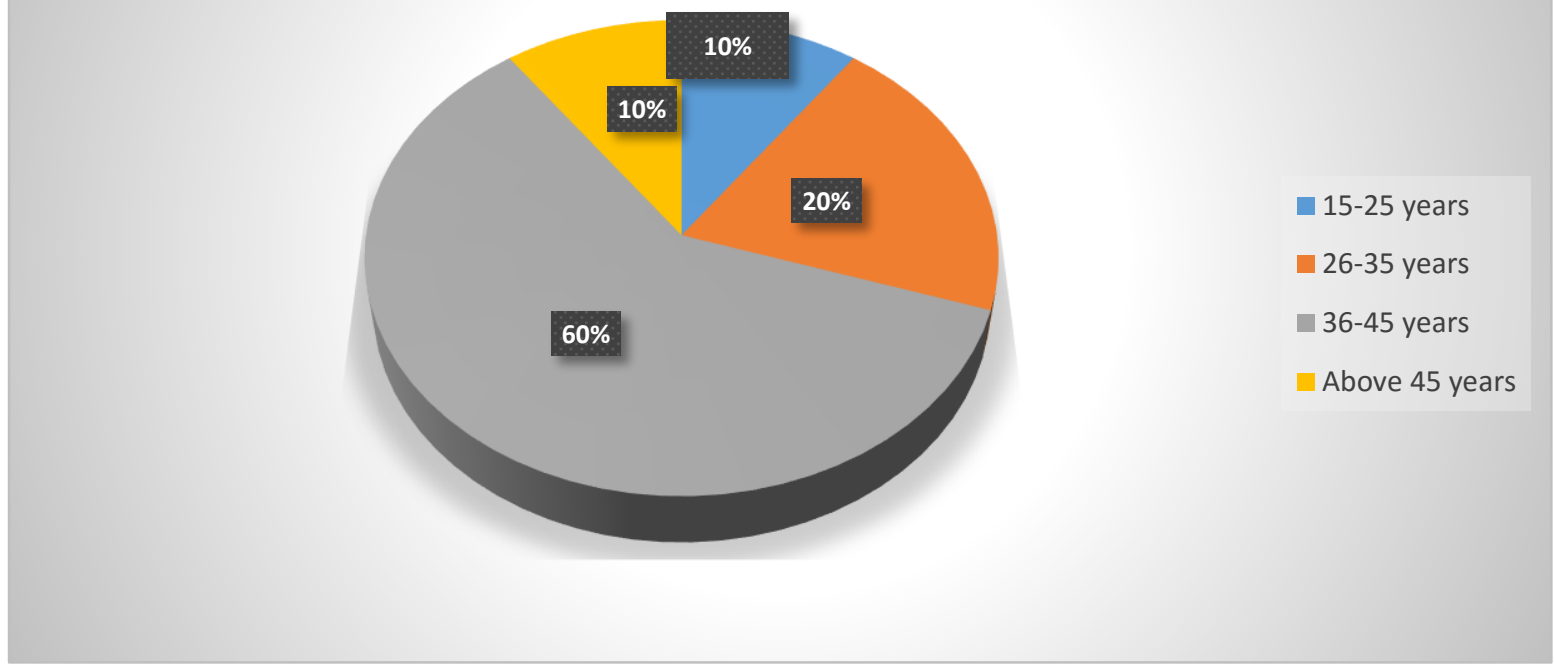

Source: Field Survey,2019

From Figure 1, it is clear that most (60\%) of the respondents who participated in the pilot study were between the ages of 36-45 years, followed by those within the age brackets of 26-35 years $(20 \%)$, then $15-25$ years $(10 \%)$ and the remaining $10 \%$ were those above 45 years. This implies that a vast majority of the respondents are middle age and are therefore economically active people. This confirms distance education literature which states that distance education students are matured.

\section{Gender Distribution of Respondents}

There were more males than females among the heavily scheduled professional Post Graduate Diploma in Education (PGDE) students who participated in the study. Figure 2 displays the gender distribution of respondents. 


\section{2nd International Conference on \\ New Trends in Teaching and Education}

29-31 October, 2020

London, United Kingdom

Figure 2: Gender Distribution of Respondents

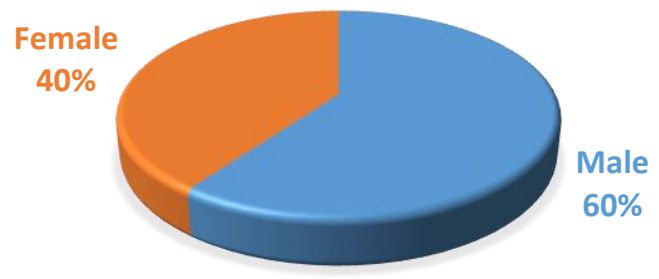

Source: Field Survey, 2019

More than half $(60 \%)$ of the students who participated in the pilot study were males whilst the remaining $(40 \%)$ were females.

\section{Occupational Distribution of Respondents}

The researchers were equally interested in knowing the kind of work that these students are engaged in. Figure 3 gives a vivid description of the various occupations of the respondents. Their occupations included banking, force work, health work and business. Engaging in these occupations at the same time schooling can indeed be very involving. Some of the respondents indicated that they come all the way from Asikuma-Odobin Brakwa, Mankessim and Akim Oda environs in the Central Region of Ghana, to attend tutorials at the Winneba Study Centre on weekends.

Fig. 3: Occupational distribution of Respondents

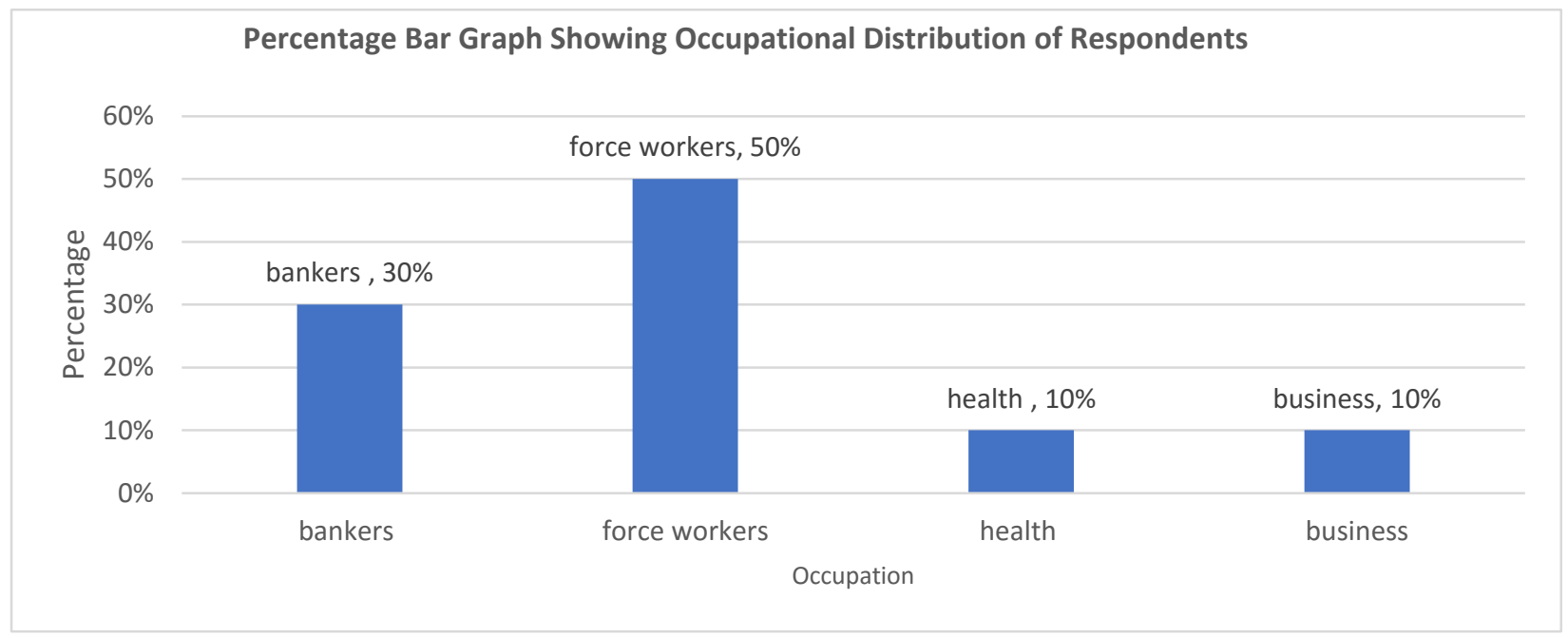

Source: Field Survey, 2019

Force workers, constituted $50 \%$ of the respondents for the study. This was followed by bankers who made up $30 \%$, then health workers $10 \%$ and finally followed by businessmen and women 
who also made up another $10 \%$. These aforementioned occupations apparently demand a lot from these student workers. This confirms distance education literature that most distance education students combine work and study. The impact of the telegram app for learning would be felt most by these workers, compared with their less busy scheduled colleagues. These constituted the occupational distribution of the respondents who participated in the study.

\section{Analysis of Research Questions}

There were two main research questions that were formulated with the aim of finding out from the students their impressions about the Telegram App with specific reference to the delivery of learning modules and the convenience of the app when it comes to student learning. This came up as pronounced challenges distance education students face. The discussion that follows is organized in line with these two research questions:

Research Question One: What are the experiences of PGDE students in the use of Telegram Social Media App for delivery of learning modules?

Table 1: Views of PGDE Distance students of UEW Study Centre on Learning Modules

\begin{tabular}{lccc}
\hline \multicolumn{1}{c}{ Statement } & Somewhat Agree & Strongly Agree & Disagree \\
\hline $\begin{array}{l}\text { 1. When hard copy learning modules delay in } \\
\text { reaching me, the Telegram App aids my learning }\end{array}$ & $6(10 \%)$ & $53(88.3 \%)$ & $1(1.7 \%)$ \\
$\begin{array}{l}\text { 2. I get files (audio, videos, pdfs) embedded in } \\
\text { lectures to support my off-campus learning }\end{array}$ & $18(30 \%)$ & $41(68.3 \%)$ & $1(1.7)$ \\
$\begin{array}{l}\text { lessons } \\
\begin{array}{l}\text { 3. Telegram App aided the completion of my } \\
\text { learning modules on time }\end{array}\end{array}$ & $12(20 \%)$ & $48(80 \%)$ & - \\
\hline
\end{tabular}

Source: Field Survey, 2019

From Table 1, it is evident that the students were satisfied with the delivery of learning materials via the telegram app. This came to light when they were asked a number of questions which pointed at their impressions about the mode of delivery of learning modules via telegram.

They agreed that when there are delays in the arrival of hard copy learning materials, the telegram app aids their learning. They confirmed this by indicating that their lecturer uploaded the softcopy of the learning module on their telegram group page and learning is therefore uninterrupted irrespective the delay in the arrival of hard copy learning modules. In all, 53 out of the 60 students, representing $88.3 \%$ strongly agreed with the assertion that when hard copy learning modules delay in reaching them, the Telegram App aids in their learning. However, none of the respondents disagreed with any of the statements. This finding is in affirmation with the assumption of McCarthy [31] that although some concerns have been raised as to the suitability and value of social media for formal teaching and learning, the general consensus is that learning has evolved from the traditional step by step learning to learning through connections with people as manifested in the social media environment.

Again, $68.3 \%$ of the students strongly agreed that their off-campus learning was enhanced by the fact that the lecture notes and slides that are uploaded for student's attention via the Telegram app had embedded in them videos, audios and pictures which made the 
comprehension of complex concepts easy. Completion of learning modules on time was yet another assertion that the students agreed to; thanks to the telegram app. Eighty percent $(80 \%)$ of the respondents indicated that the use of the telegram app in teaching and learning had in no small way resulted in the early completion of their learning modules. They highlighted further that owing to the fact that they had the modules and lecture notes comfortably situated in the telegram app on their android phones, learning took place at anytime and anywhere. This finding also affirms the works of Cubukcuo lu [9] that social networks could be one of the solutions to utilize virtual learning environments anytime, anywhere, and at any pace.

From the qualitative point of view, the respondents were given the opportunity to elaborate more on the reasons why they are of the view that the telegram app facilitates the timely delivery of learning modules. Their responses were categorized under the following themes: ease of access to lecture slides, learning module delivery, ease in downloading of different file formats. as follows:

The researchers inquired from respondents whether learning takes place using the telegram app when there is a delay in the delivery of learning modules, this is what Joe, a banker had to say

\section{Yes. Learning can take place because our lecturer prepares the lecture slides from the softcopy of our modules. Then after we get the modules, we just continue from where we got to; and finish our module on time.}

This implies that there is an easy access to lecture slides and timely completion of modules which is in support with statements 1 and 3 on Table 1. This affirms the works of Powell et al [38] who argued that social media relies on computer-mediated technologies that allow the creating and sharing of information, ideas, career interests and other forms of expression through virtual communities and networks.

In another instance, Sabina, health worker had this to say:

Because soft copies of the module are available via telegram, I am able to prepare in advance which is in no way affected by the delay in the hard copy modules.

Not so different from Sabina, John a force worker had this to say about his impression about the telegram app with respect to learning module delivery:

Telegram App aided the completion of my learning module on time (soft copies enable me to prepare ahead of time before arrival of hard copies.

In this regard, it is implied that with the aid of the telegram app, students are able to prepare in advance before hard copy modules get to them. This is in tune with statement 2 on Table 1. Peter a businessman had this to say about the telegram app: 
With the telegram app, I am able to receive lecture notes from my lecturer with ease. In addition, I am able to download easily, files in various formats e.g. avi, jpeg, mp4,pdf, PowerPoint etc. All these support my off campus learning lessons.

This finding goes to mean that the telegram app makes provision for easy downloading of different file formats which goes a long way to facilitate student learning. This agrees with the works of Taylor [43] who highlighted various generational stages when it comes to the evolution of distance learning. According to Taylor [43] the fourth-generation stage is characterized by the flexible learning model which has features including interactive multimedia online, internet - based access to www resources and computer-mediated communication which makes room to easy downloading of files of various formats including avi, mp4, jpeg etc.

On the contrary however, the study recorded a weak negative comment from one of the respondents. James, a teacher in a remote community in the Central Region had this to say:

"I am not good at computing so I don't see much of this app.

I am unable to download the slides that are sent by the lecturer.

Infact, my village is not on the national grid, most of us therefore

use non-android phones which does not support telegram.

I am therefore inconvenienced when it comes to this app.'

Research Question Two : How convenient is the Telegram Social Media App to PGDE students of UEW?

The second research question sought to investigate the convenience level of the telegram app when it comes to student learning. Five statements were formulated to assess the convenience levels of telegram app, respondents were required to indicate the extent to which they were either satisfied or dissatisfied with the statements. Their responses are presented in Table 2.

Table 2: Convenience of Telegram App

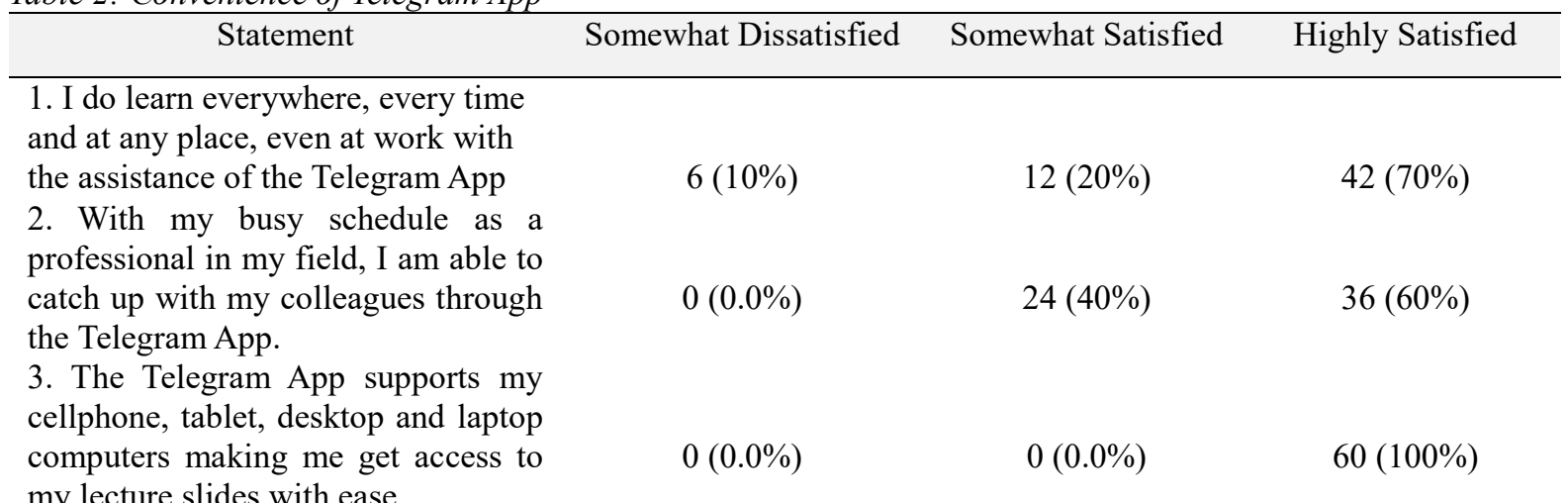


4. As a student, I am able to reach my lecturer one on one for clarity of lessons which I missed out on with ease via Telegram

$6(10 \%)$

$12(20 \%)$

$42(70 \%)$

5. In instances that due to tight office schedules I miss my virtual class, I still get access to all discussions and slides via Telegram

Source: Field Survey, 2019

From Table 2, it can be inferred that the students are highly satisfied with the app when it comes to the role the app plays with respect to learning convenience. They indicated among other things that indeed they learn everywhere, every time and even at any place, including their places of work. Irrespective their busy professional schedules, $60 \%$ of them indicated that they were highly satisfied with the app because it assisted them to catch up with their other student colleagues. In addition, $70 \%$ of them also indicated that they were highly satisfied with the fact that through the app, they are able to easily contact their lecturer.. Finally, all the students indicated in the affirmative that instances that they are unable to actively participate in the virtual lesson owing to loaded office schedules, they are still able to access the discussions and slides later, which means, they do not miss out much on what is taught in the virtual class.

This finding is in consonance with the works of Juang [19] which argued further that, as the history of communications reveals, the idea of sharing your personal experiences with others and feeling connected to the larger world is not new: what is new is efficiency. Due to the access of computers, tablets, and phones, people are posting more and more to social media. The technological changes in social media have continued to advance rapidly, transforming older technologies to make them simpler and more effective.

From the qualitative research point of view, the researchers delved more into finding out from the respondents a vivid description of the features that telegram app has which makes them conclude that it is a more convenient app for learning.

In the words of Patricia, a force worker:

Learning everywhere, every time and at any place, even at work with the assistance of the Telegram App etc

This response can be relayed with the response on Table 1 statements 1 and 2 where the respondents are in agreement that learning takes place everywhere which makes it very convenient for their studies.

In a similar instance, Sabina who is a health worker indicated that she can easily catch up with her colleagues with the aid of the telegram app. She had this to say in support of her assertion:

I am able to catch up with my colleagues through the Telegram App. I am able to access with ease the class discussions, slides and assignments. In addition, I am able to access the tutorials and slides on a later date should I run out of airtime on my device or due to my tight office schedules. 
This finding is in conformity with the response on Table 1 with respect to statements 2 and 5 . These findings are supported by Tedd [44] who opined that with "virtual learning, students can study at a time and location that suits them and can quickly locate misplaced notes".

Another respondent had this to say with respect to the convenience of the telegram app when it comes to virtual learning. She is Felicia, a 36-year-old banker:

\section{Telegram App supports my cellphone, tablet, desktop and laptop computers making me get access to my lecture slides with ease.}

Similarly, Henry, a force worker with a sign of relief expression on his face indicated that through the app, he is able to easily reach his lecturer for clarification on lessons he missed out on. He added that the discipline which the lecturer instilled and the ground rules that the class agreed on with respect to the use of the platform ensures that the platform is used strictly for academic purposes, this also encourages the lecturer to easily respond to concerns of busy scheduled student workers like myself. Here is his quote:

"I am able to reach my lecturer one on one for clarity of lessons

which I missed out on the platform with ease via Telegram”

Both responses above are in line with the responses on Table 1 with respect to statements 3 and 4. These findings are supported by www.telegram.org which it is clearly stated that "Telegram supports multi-device sessions, one can start chatting on one device and continue it on another. All the messages too are synced between devices in real time, so it's quick and efficient. A user can even check his/her active sessions in the app to know the devices in which his/her Telegram account might be active. This means it supports digital tablets, android, windows and apple brand cellphones as well".

\section{Conclusion}

The study draws two conclusions, a conclusion for each research question. With respect to the first research question which sought to find out from the heavily scheduled students their perceptions about the telegram app when it comes to the delivery of lesson modules, telegram proved to be a very efficient app in delivery learning modules for the students. With respect to the convenience of the telegram app for distance learning, the study also concludes by stressing how useful and extremely convenience the app has been for these busy scheduled distance students.

\section{Recommendation}

The study recommends the adoption and integration of telegram app in an attempt to resolve the late delivery of learning modules as well as learning convenience for distance education students of the Institute for Distance and eLearning of the University of Education, Winneba.

\section{Acknowledgement}

We are grateful to all the Post Graduate Diploma in Education Distance Students of University 


\section{2nd International Conference on \\ New Trends in Teaching and Education}

29-31 October, 2020

London, United Kingdom

NEW TRENDS

IN TEACHING

of Education, Winneba for actively participating in the study. We are equally grateful to the reviewers for their comments and suggestions.

\section{References}

[1] Berge, Z.L., Muilenburg, L.Y., \& Haneghan, J.V. (2002). Barriers to distance education and

training: Survey results. The Quarterly Review of Distance Education, 3(4), 409-418.

[2] Berlanga, A. J., M. E. Bitter-Rijpkema, F. Brouns, P. B. Sloep, \& S. Fetter. (2009). Personal

Profiles: Enhancing Social Interaction in Learning Networks. - International Journal of

Learning Technology-IJLT. 4(5), 305-318.

[3] Bhalalusesa, E. (1998). The distance mode of learning in higher education: The Tanzanian experience. Open learning, 14(2), 14-23.

[4] Bhalalusesa, E. (1999). What Retain students in the programme? Reflection from the Open

of

University of Tanzania. In Papers in education and Development. A journal of faculty education University of Dar es salaam. Number 20.

[5] BrckaLorenz, A. \& A. K. Garver. (2010). Interactive Technology and Effective Educational Practices. Paper Presented at AIR Conference.

[6] Carr, S. (2000). As distance education comes of age, the challenge is keeping the students. The chronicle of higher education, 46(23), 47-61.

[7] Cosmas, B. F., \& Mbwette, T.S. (2009). Open and distance learning in developing countries:

The past, the present and the future. Dar es salaam: Open University of Tanzania.

[8] Cross, K.P. (1981). Adults as learners. San Francisco: Jossey-Bass.

[9] Cubukcuo lu, A. B. (2012). Social Networks as a Virtual Teaching and Learning Environment in Higher Education.

[10] Daniel, S. (2000). Collaborative learning: improving public deliberation in ecosystembased

management, Environmental Impact Assessment Review, 16, pp. 71-102. 


\section{2nd International Conference on \\ New Trends in Teaching and Education}

29-31 October, 2020

London, United Kingdom

[11] Daniel, J. (2005). Open and Distance Learning in Africa.15CCEM Mid-Term. Educational media international, 39(1), 17-22.

[12] Fozdar, B., Kumar, S. A., \& Kannan, S. (2006). A Survey of study on the reasons responsible for student drop-out from the Bachelor of Science programme at Indira Gandhi National Open University: IGNOU Press.

[13] Garland, M. (1993). Ethnography penetrates the "I didn't have time" rationale to elucidate higher

order reason for distance education withdrawal. Research in distance education, 8(2), 181-198.

[14] Grodecka, K., K. Pata \& T. Valjataga. ( 2008).Web 2.0 and Education. How to Use Social

Software in Higher Education. A handbook from iCamp Project.

[15] Heibert, G. \& R. Harper. (2008). Have You Facebooked Astin Lately? Using Technology

to $\quad$ Increase Student Involvement. In J. H. Schuh(Editor-in-chief), E. J. Whitt (Ass. Ed.),

R.Junco, D. M. Timms (Eds.). Using Emerging Technologies to Enhance Student Engagement.

New Directions for Student Services, 124.

[16] Hung, H. \& S. C. Yuen. (2010). Educational Use of Social Networking Technology in Higher

Education. Teaching in Higher Education, (15) 6, 703-714.

[17] Junco, R \& G. A. Cole-Avent. (2008). An Introduction to Technologies Commonly Used

by College Students. In J. H. Schuh(Editor-in-chief), E. J. Whitt (Ass. Ed.), R. Junco, D. M.

Timms(Eds.). Using Emerging Technologies to Enhance Student Engagement. New Directions

for Student Services, 124.

[18] Juang, Y. (2010). Integrating Social Networking Site into Teaching and Learning. S. L. Wong et

al. (Eds.). Proceedings of the $18^{\text {th }}$ International Conference on Computers in Education. Putrajaya, Malaysia: Asia-Pacific Society for Computers in Education.

[19] Kamau, J. (2007). Retraining primary school teachers against diminishing resources: Is 


\section{2nd International Conference on \\ New Trends in Teaching and Education}

29-31 October, 2020

London, United Kingdom

NEW TRENDS

IN TEACHING

distance education the answer? Conference paper, UNESCO, second regional seminar for Africa, Accra Ghana; UNESCO.

[20] Kember, D. (1989). A longitudinal-process model of drop-out from distance education. Journal of higher education, 60(3), 278-301.

[21] Kidwell, R.P.; Linde M. \& Johnson, T. (2000). A survey into the application of ICT for educational purposes in higher education (pp. 176 - 181). Rottrtdsm: Erasmus Universiteit/OECR.

[22] Kop, R., \& Hill, A. (2008). Connectivism: Learning theory of the future or vestige of the past?. The

International Review of Research In Open And Distance Learning, 9(3).

[23] Kör, H. (2013). Uzaktan ve Örgün Eğitimin Öğrenci Başarısı Üzerine Etkisinin Araştırılması, Gaziantep Ünversitesi Sosyal Bilimler Dergisi. Gaziantep University Journal of Social Sciences, 12(2), 267-279.

[24] Kör, H., Erbay, H., Demir, E., \& Akmeşe, Ö. F. (2016). A study on the factors affecting the

academic performance of distance education students and formal students, Hit it. University Journal of Social Sciences Institute, 9(2), 1029-1050.

[25] Krejcie, R.V., \& Morgan, D.W., (1970). Determining Sample Size for Research Activities.

Educational and Psychological Measurement.

[26] Kruger, R. A. \& Casey, M. A. (2000). Focus Groups: A practical guide for Applied Research, $3^{\text {rd }}$ ed . London: SAGE.

[27] Madge, C., J. Meek, J. Wellens \& T. Hooley. (2009). Facebook, Social Integration and Informal Learning at University: 'It is More for Socializing and Talking to Friends about Work than for Actually Doing Work'. Learning, Media and Technology, 34 (2), 141-155.

[28] Mbukusa, N.R. (2009). Barriers to rural remote students' access of distance education supports services offered by the centre for External studies at the University of Namibia. Pretoria: University of South Africa.

[29] Mushi, P .S.D. (2001). Prospects of combining residential and distance mode of university education in Tanzania In UTAFI, News Series Special Issue, Volume 4,1998-2004:221-255.

[30] McCarthy, J. (2010). Blended learning environments: using social networking sites to enhance the rest year experience. Australasian Journal of Educational Technology, 26(6):729-740. 


\section{2nd International Conference on \\ New Trends in Teaching and Education}

29-31 October, 2020

London, United Kingdom

NEW TRENDS

IN TEACHING

[31] Mehrotra, C. M., Hollister, C. D., \& McGahey, L. (2001). Distance learning: Principles for effective design, delivery, and evaluation. Thousand Oaks, CA: Sage Publications, Inc.

[32] Moody, M. (2010). Teaching Twitter and Beyond: Tip for Incorporating Social Media in Traditional

Courses. Journal of Magazine \& New Media Research 11(2): pp. 1-9.

[33] Mossberger, K., Tolbert, C. \& Stansbury, M. (2003). Virtual inequality: Beyond the digital divide.

Washington, D. C.: Georgetown University Press.

[34] OECD. (2000). Beyond Rhetoric: Adult Learning Policies and Practices. Paris:

OECD. Retrieved

from. www.springerlink.com/...gp636820v09671k2.pd. on 04/11/2018.

[35] Ololube, N.P. (2006). ICT and distance education in Nigeria: a review of literature and accounts. Accessed on 26th September 2017 from

http://www.educause.edu/LibraryDetailPage/666\&ID=PUB8001

[36] Oradini, F. \& G. Saunders. (2008). The Use of Social Networking by Students and Staff in Higher Education. Paper Presented at the iLearning Forum, Paris. Retrieved March 25, 2010, from

http://www.eife-l.org/publications/proceedings/ilf08/contributions/improving-qualityof-learning-with-technologies/Oradini_Saunders.pdf

[37] Powell, Guy, R., Groves, Steven, W. \& Dimos, Jerry. (2011). ROI of Social Media: How to Improve the Return on Your Social Marketing Investment. New York: John Wiley and Sons.

[38] Reiser, R. A., \& Dempsey, J. V. (2012). Trends and issues in instructional design and technology (3rd ed.) Upper Saddle River, NJ: Erlbaum.

[39] Ryan, M. (1997). Education Casts Wide Net. Tech Web News.

[40] Solomon, C. \& K. Schultz. (2007). Using Online Social Networks to Support Underrepresented Students' Engagement in Postsecondary Education. Proceedings of the 8th International

Conference on Computer Supported Collaborative Learning (CSSCL). Retrieved March, $\quad 8,20$, from ACM Digital Library.

[41] Taylor, J.C. (1995). 'Distance education technologies: The fourth generation'. Australian Journal of

Educational Technology, 11, 2, pp. 1-7. 
[42] Tedd, M. (2008). Thirty-two trends affecting virtual education: An informed foundation for strategic planning. Online Journal of Distance Learning Administration 6, (3), 13.19. Retrieved on 23rd May, 2010 from http://www.surf.ni/wtr/en/.

[43] Zirnkle, C. (2001). Access barriers in distance education. Contemporary education 72 (2), 39-42.

https://telegram.org

\section{References}

[1] Berge, Z. L., Muilenburg, L.Y. and J.V. Haneghan, (2002). Barriers to distance education and training: Survey results. The Quarterly Review of Distance Education, 3(4), 409-418.

[2] A. J. Berlanga, M. E. Bitter-Rijpkema, F.

Brouns, P. B. Sloep, and S. Fetter, "Personal

Profiles: Enhancing Social Interaction in

Learning Networks". - International Journal of Learning Technology- IJLT, 2009.

[3] E. Bhalalusesa, The distance mode of learning in higher education: The Tanzanian experience. Open learning, 1998, 14(2), 14-23.

[4] E. Bhalalusesa, "What Retain students in the programme? Reflection from the Open University of Tanzania". In Papers in education and Development. A journal of faculty of education University of Dar es salaam. 1999, Number 20.

[5] A. BrckaLorenz, and A. K. Garver, Interactive Technology and Effective

Educational Practices. Paper Presented at AIR Conference. 2010.

[6] S. Carr, As distance education comes of age, the challenge is keeping the students. The chronicle of higher education, 2000, 46(23), 47-61.

[7] B. F. Cosmas, and T.S. Mbwette, "Open and distance learning in developing countries: The past, the present and the future". Dar es salaam: Open University of Tanzania, 2009.

[8] Cross, K.P, Adults as learners. Jossey-Bass San Francisco, 1981.

[9] A. B. Cubukcuo lu, Social Networks as a Virtual Teaching and Learning Environment in Higher Education, 2012.

[10] S. Daniel, Collaborative learning: improving public deliberation in ecosystembased management, Environmental Impact Assessment Review, 2000. 16, pp. 71-102.

[11] J. Daniel, Open and Distance Learning in Africa.15CCEM Mid-Term. Educational media international, 2005, 39(1), 17-22.

[12] T.S. Deration, "Absenteeism among distance students at tutorials". Teaching and Learning in Higher Education, 2000.

[13] B. Fozdar, S. A. Kumar, and S. Kannan, 
A Survey of study on the reasons responsible for student drop-out from the Bachelor of Science programme at Indira Gandhi National Open University: IGNOU Press, 2006.

[14] M. Garland, "Ethnography penetrates the "I didn't have time" rationale to elucidate higher order reason for distance education withdrawal". Research in distance education, 1993, 8(2), 181-198.

[15] K. Grodecka, K. Pata and T. Valjataga, Web 2.0 and Education. How to Use Social

Software in Higher Education. A handbook

from iCamp Project. 2008

[16] G. Heibert, and R. Harper, Have You

Facebooked Astin Lately? Using Technology to Increase Student Involvement. In J. H. Schuh(Editor-in-chief), E. J. Whitt (Ass. Ed.), R.Junco, D. M. Timms (Eds.). Using Emerging Technologies to Enhance Student Engagement. New Directions for Student Services, 124. 2008.

[17] H. Hung, and S. C. Yuen. "Educational Use of Social Networking Technology in Higher Education". - Teaching in Higher Education, 2010, (15) 6, 703-714.

[18] R. Junco, and G. A. Cole-Avent. An Introduction to Technologies Commonly Used by College Students. In J. H. Schuh(Editor-in-chief), E. J. Whitt (Ass. Ed.), R. Junco, D. M. Timms(Eds.). Using Emerging Technologies to Enhance Student Engagement. New Directions for Student Services, 124, 2008.

[19] Y. Juang, "Integrating Social Networking Site into Teaching and Learning”. S. L. Wong et al. (Eds.). Proceedings of the $18^{\text {th }}$ International Conference on Computers in Education. Putrajaya, Malaysia: Asia-Pacific Society for Computers in Education, 2010.

[20] J. Kamau, Retraining primary school teachers against diminishing resources: Is

distance education the answer? Conference paper, UNESCO, second regional seminar for Africa, Accra Ghana; UNESCO, (2007).

[21] D. Kember, "A longitudinal-process model of drop-out from distance education". Journal of higher education, 1989, 60(3), 278-301.

[22] R.P. Kidwell, M. Linde and T. Johnson, A survey into the application of ICT for educational purposes in higher education, 2000. (pp. 176 - 181). Rottrtdsm: Erasmus Universiteit/OECR.

[23] R. Kop, and A. Hill, "Connectivism:

Learning theory of the future or vestige of the past?." The International Review of Research In Open And Distance Learning, 2008. 9(3).

[24] H. Kör, "Uzaktan ve Örgün Eğitimin Öğrenci Başarısı Üzerine Etkisinin Araştırılması, Gaziantep Ünversitesi Sosyal Bilimler Dergisi.” Gaziantep University Journal of Social Sciences, 2013. 12(2), 267-279.

[25] H. Kör, H. Erbay, E. Demir, and Ö. F. Akmeșe, "A study on the factors affecting the 
academic performance of distance education students and formal students, Hit it". University Journal of Social Sciences Institute, 2016, 9(2), 1029-1050.

[26] R.V. Krejcie, and D.W. Morgan,

Determining Sample Size for Research Activities. Educational and Psychological Measurement. 1970.

[27] R. A. Kruger, and M. A. Casey, Focus Groups: A practical guide for Applied Research, $3^{\text {rd }}$ ed . London: SAGE. (2000)

[28] C. J. Madge, R. Meek, J. Wellens \& T. Hooley, "Facebook, Social Integration and Informal Learning at University: 'It is More for Socializing and Talking to Friends about Work than for Actually Doing Work'”. Learning, Media and Technology, 2009. 34 (2), 141-155.

[29] N. R. Mbukusa, Barriers to rural remote students' access of distance education supports services offered by the centre for External studies at the University of Namibia. Pretoria: University of South Africa, 2009.

[30] P. S. D. Mushi, Prospects of combining residential and distance mode of university education in Tanzania In UTAFI (News Series Special Issue, 2001. Volume 4,19 98-2004:221-255.

[31] J. McCarthy, "Blended learning environments: using social networking sites to enhance the rest year experience". Australasian Journal of Educational Technology, 2010, 26(6):729-740.

[32] C. M. Mehrotra, C. D. Hollister, and

L. McGahey, Distance learning:

Principles for effective design, delivery, and evaluation. Thousand Oaks, CA: Sage Publications, Inc. 2001.

[33] M. Moody, "Teaching Twitter and

Beyond: Tip for Incorporating Social Media in Traditional Courses". Journal of Magazine \& New Media Research, 2010, 11(2): pp. 1-9.

[34] K. Mossberger, C. Tolbert, and M. Stansbury, Virtual inequality: Beyond the digital divide. Washington, D. C.: Georgetown University Press, 2003.

[35] OECD. Beyond Rhetoric: Adult

Learning Policies and Practices. Paris: OECD. Retrieved from. www.springerlink.com/.../gp636820v09671k2.pd. on 04

$/ 11 / 2018,2000$.

[36] N. P. Ololube, ICT and distance education in Nigeria: a review of literature and accounts. Accessed on 26th September 2018 from http://www.educause.edu/LibraryDetailPage/666\&ID=PUB8001, 2006.

[37] F. Oradini, and G. Saunders. The Use

of Social Networking by Students and Staff in Higher Education. Paper Presented at the iLearning Forum, Paris, 2008. Retrieved March 25, 2018, from http://www.eife1.org/publications/proceedings/ilf08/contributions/improving-qualityof-learning-with-technologies/Oradini_Saunders.pdf

[38] J. Powell, R. Guy, P. Groves, W. Steven, and J. Dimos, ROI of Social Media: How to improve the Return on Your Social Marketing Investment. New York: John Wiley and Sons, 2011. 


\section{2nd International Conference on \\ New Trends in Teaching and Education}

29-31 October, 2020

London, United Kingdom

[39] R. A. Reiser, and J. V. Dempsey, Trends and issues in instructional design and technology (3rd ed.) Upper Saddle River, NJ: Erlbaum, 2012.

[40] H. Robinson, "Category of distance students worse hit by distance education challenges". Journal of Distance \& New Media Research, 2004, 11(2): pp. 11-17.

[41] M. Ryan, Education Casts Wide Net. Tech Web News, 1997.

[42] C. Solomon, and K. Schultz, "Using Online

Social Networks to Support Underrepresented

Postsecondary Education. Proceedings of the 8th International

Conference on Computer Supported Collaborative Learning (CSSCL). Retrieved March, $\quad$ 8, 2007 from ACM Digital Library.

[43] J.C. Taylor, 'Distance education

technologies: The fourth generation'. Australian Journal of Educational Technology, 1995, 11, 2, pp. 1-7.

[44] M. Tedd, Thirty-two trends affecting virtual education: An informed foundation for strategic planning. Online Journal of Distance Learning Administration 6, (3), 13.19. Retrieved on 23rd May, (2008). from http://www.surf.ni/wtr/en/.

[45] M. Trait, Issues of Distance

Students. Educational Strategies, 2002.

[46] C. Zirnkle, "Access and barriers in

distance education". Contemporary education ,2001, 72 (2), 39-42.

[47] https://telegram.org 